\title{
Burden of adult neurofibromatosis 1: development and validation of a burden assessment tool
}

\author{
Marie-Laure Armand ${ }^{1}$, Charles Taieb ${ }^{2 *}$, Aline Bourgeois ${ }^{1}$, Mireille Bourlier ${ }^{3}$, Mohammed Bennani ${ }^{4}$, \\ Christine Bodemer ${ }^{2,5}$, Pierre Wolkenstein ${ }^{1}$ and along with the French national network on rare skin diseases \\ (FIMARAD)
}

\begin{abstract}
Background: Neurofibromatosis Type 1 (NF1) is a common genetic neurocutaneous disease, with an autosomal dominant inheritance mode. Quality of life has been shown impaired in NF1, due to severe complications, cosmetic features, and uncertainty about the disorder.

Methods: This study sought to develop a self-administered questionnaire in French to assess the burden of NF1 $(\mathrm{BoN})$, then translate and linguistically and cross-culturally validate it into American English, standardized methodology applied, as outlined in the report.

Results: Based on several discussions with NF1 patients, a 17-item conceptual questionnaire was first produced. Of the 91 NF1 adult patients who responded to the conceptual questionnaire, 65 (64.6\% females) were accessible. Subsequent confirmatory analyses generated a 15-item questionnaire grouped into four domains, demonstrating internal consistency (Cronbach's alpha: 091), discriminant validity, and high reliability. The BoN was likewise shown to significantly correlate with other validated questionnaires, such as Dermatology Life Quality Index, Perceived Stress Scale, and SF12 mental score, indicating good external validity.

Conclusions: BoN is a specific tool for assessing the burden that NF1 generates on many practical aspects of the patient daily activities, beyond the notion of quality of life". Given the increasing relevance that regulatory authorities attribute to patient-reported outcomes, the BoN questionnaire provides such supplementary information while accounting for the burden of NF1 patients in the broadest sense.
\end{abstract}

Keywords: Neurofibromatosis type 1, NF1, Von Recklinghausen's disease, Individual disease burden, Quality of life, Questionnaire

\section{Background}

Neurofibromatosis Type 1 (NF1) is the most common autosomal dominant neurocutaneous disease, caused by mutations in the NF1 tumor suppressor gene, located in a region on chromosome 17ql1.2 [1]. This gene encodes a common protein, namely neurofibromin, which is an essential negative regulator of Ras cellular proliferation pathways [2, 3]. Disease prevalence is estimated at

\footnotetext{
* Correspondence: charles.taieb@emma.clinic

${ }^{2}$ FIMARAD, French rare diseases Healthcare Network: rare dermatologic disease, CHU Paris - Hôpital Necker-Enfants Malades, 149 rue de Sèvres, 75743 Paris, France

Full list of author information is available at the end of the article
}

1:2000-1:3500 individuals worldwide, yet with wide phenotypical variability [4-6]. The germline NF1 mutation rate proves ten-fold higher than that observed in other inherited disease genes [7].

Establishing the correct NF1 diagnosis may prove challenging [8]. NF1 patients are at increased risk of developing various tumors, and their life-expectancy is decreased by 10 years as compared to the general population [9]. With skin lesions as the most noticeable disease manifestation, NF1 may affect many organs, and psychiatric and psychological disorders are likewise common $[10,11]$. Around $20 \%$ of patients display dysthymia and $7 \%$ depressed mood, with a heightened risk of

(c) The Author(s). 2019 Open Access This article is distributed under the terms of the Creative Commons Attribution 4.0 International License (http://creativecommons.org/licenses/by/4.0/), which permits unrestricted use, distribution, and 
suicide [12]. Anxiety and personality disorders are similarly observed, and cognitive disorders may last into adulthood, thereby impacting smooth integration into work [13]. Quality of life (QoL) was shown impaired in NF1 patients, especially in severe disease cases [14].

The concept of "burden" has taken a central role in evaluating care [15], and specifically in case of skin diseases [16]. In 2010, the World Health Organization first introduced the concept of "Global Disease Burden", particularly useful for quantifying population health and determining action priorities [17]. The focus has meanwhile been switched to "individual disease burden", a concept designed to assess disease "disability" in the broadest sense, including psychological, social, economic, and physical features. Such individual disease burden was already investigated in skin diseases like psoriasis [18], infantile hemangioma [19], hereditary ichthyosis [20], atopic dermatitis [21], and vitiligo [22].

Ferner et al. [23] have developed a disease-specific questionnaire to measure QOL in people with NF1 (INF1-QOL) that is suitable as an assessment tool in clinical practice and in clinical trials. The aim of our work is to assess the burden and the impact that the NF1 generates on many practical aspects of the patient daily activities in addition to the notion of quality of life.

As part of their research activities, the "reference centers for rare skin disorders" network has elaborated and validated a French questionnaire designed to assess the burden of NF1 on patients suffering from the condition, termed Burden of Neurofibromatosis (BoN). This paper describes the different steps involved.

\section{Methods}

The self-administered BoN questionnaire was developed using standard methodology comprising three phases, namely exploratory, development, and validation [24]. This questionnaire was developed by a multidisciplinary working group comprising experts in questionnaire design/development, such as healthcare professionals like physicians and psychologists, experts in NF1, such as social workers and dermatologists, as well as experts in QoL and patient-reported outcomes.

The questionnaire was conventionally created in a question and answer format. Response modalities were determined via consensus among the experts, and took the form of a 6-point Likert scale: "never" (0), "rarely" (1), "sometimes" (2), "often" (3), "very often" (4), and "constantly" (5). To limit missing data, we also considered a "not applicable" (0). Instructions in the preamble state that the questions relate to the previous 30 days. Subjects from the age of 15 could complete the questionnaire and had the option to indicate "not concerned" for non-applicable questions.

\section{Exploratory phase}

The initial step involved several one-to-one interviews between the dermatologist, psychologist, social worker, and expert in patient-reported outcomes with patients suffering from NF1 to comprehensively collect the patients' perceptions and complaints. By analyzing these interviews, the most relevant concepts were identified. A semi-structured questionnaire was then elaborated comprising specific themes in a question/answer format, including closed-ended questions with a choice of predetermined answers, as well as open-ended questions allowing unrestricted answers. The final choice of questions was made by the working group.

\section{Development phase}

During this phase, the conceptual questionnaire was administered to a sample of subjects suffering from the disease. An exploratory factor analysis was conducted to highlight the underlying constructs, assigning each item to its respective domain, with orthogonal varimax rotation performed to verify whether the hypothetical constructs were interrelated.

To evaluate the questionnaire's internal consistency and confirm its reliability, the item homogeneity in each dimension was tested using Cronbach's alpha coefficient [25]. Higher order factor confirmatory analysis was performed to confirm that the dimensions created could be combined into one single score. PROC CALIS procedure, SAS 9.4, was employed. The criteria for the model's goodness-of-fit were defined as a Bentler comparative fit index $>0.90$, and Bentler-Bonett non-normed fit index $>0.90$ [26], with root mean square error of approximation (RMSEA) close to 0.05 or at the very least less than 0.08 .

\section{External validity}

To assess the questionnaire's external validity, all participants were asked to complete three previously validated self-administered questionnaires: the Dermatology Life Quality Index [DLQI] questionnaire,

The DLQI questionnaire is the first dermatology-specific instrument designed to assess the impact of skin diseases on patient QoL [27, 28]. Intended for adults and patients aged over 16 years, DLQI has proven a simple, practical, and validated questionnaire that grades QoL, the DLQI score being the sum of all scores (0-30), with high scores reflecting poor QoL.

The PSS is the most widely used psychological instrument for measuring the perception of stress. Composed of 10 items rated from "never" to "often", PSS measures the degree to which situations in one's life are perceived as stressful $[29,30]$. The total score ranges from 10 to 50 , and the higher the score, the higher the stress. 
The SF12 is a short version of the SF-36, namely a generic instrument to measure population health [31], with a physical composite score and mental composite score calculated based on 12 questions, and the higher the score, the better the physical and the mental quality of life, respectively.

Concurrent validity was established by calculating Pearson correlations between the $\mathrm{BoN}$ and the other three validated questionnaires. The data were analyzed using SAS software Version 9.4 (SAS Institute, Cary, NC, USA), with the significance level set at 0.05 .

\section{Test-retest analysis}

To assess reproducibility, a test-retest analysis was conducted, with a group of subjects asked to complete the questionnaire twice, with at least a 10-day interval in-between.

\section{Translation, cross-cultural adaptation, and cognitive debriefing}

While the original BoN questionnaire was developed in French, previously-validated methodology was applied to generate an US English-language version, involving cross-cultural validation [32]. The nine steps involved are summarized in Table 1. A number of changes could be implemented throughout the validation process, so as to further improve the initial idiomatic draft.

Table 1 Principles of Good Practice for the Translation and Cultural Adaptation Process for Patient-Reported Outcomes (PRO) Measures

\begin{tabular}{|c|c|}
\hline Stage & Détails \\
\hline Preparation & $\begin{array}{l}\text { Evaluation of the source text from a } \\
\text { linguistic and cultural point of view } \\
\text { including definition of concepts }\end{array}$ \\
\hline Forward translations & $\begin{array}{l}\text { Forward translation into the required } \\
\text { target language by two independent } \\
\text { translators }\end{array}$ \\
\hline Reconciliation & $\begin{array}{l}\text { Comparison of the two forward } \\
\text { translations to provide the best adaption } \\
\text { and produce a draft version of the text }\end{array}$ \\
\hline Back translation & $\begin{array}{l}\text { Translation of the draft forward } \\
\text { translation back into the targeted } \\
\text { language without reference to the } \\
\text { original language }\end{array}$ \\
\hline Back-translation review & $\begin{array}{l}\text { Comparison of the original text and } \\
\text { the back translation to verify that the } \\
\text { meaning of the draft translation is } \\
\text { equivalent to source }\end{array}$ \\
\hline $\begin{array}{l}\text { Analysis and implementation } \\
\text { of back-translation review } \\
\text { report }\end{array}$ & $\begin{array}{l}\text { Analysis of the back-translation review } \\
\text { report to verify if there are changes } \\
\text { required to the draft forward }\end{array}$ \\
\hline Pilot testing & Clinical review and cognitive debriefing \\
\hline $\begin{array}{l}\text { Review of cognitive } \\
\text { debriefing or clinical } \\
\text { review results }\end{array}$ & $\begin{array}{l}\text { Review of the results from the cognitive } \\
\text { debriefing or clinical review to identify } \\
\text { translation modifications necessary for } \\
\text { improvement }\end{array}$ \\
\hline
\end{tabular}

\section{Results}

\section{Conceptual phase}

Over the preceding 12 months, the psychologist and co-author conducted discussions with 45 NF1 patients on a one-to-one basis concerning their complaints and distresses. Combined with the work of the social worker, this research resulted in the description of the patients' perceptions in an initial verbatim. Several one-on-one discussions between dermatologist, psychologist, social worker and expert in patient-reported outcomes contributed to consolidate this initial wording, with eventually 17 items forming the conceptual questionnaire.

\section{Development and validation phase Study population}

Patients were selected with the support of the French association of patients with neurofibromatosis, which proposed the questionnaire to previously diagnosed patients. NF1 is a rare skin disease, and working with the Association Neurofibromatoses et Recklinghausen ensured broad recruitment over the territory to guaranteed a reasonably diversity of patients in terms of geographical location, age and sociological status. Overall, 91 patients were contacted of whom 65 responded to the conceptual questionnaire. Among the respondents, $64.6 \%$ were women (Table 2 ).

The cohort's mean age was 47.74 years \pm 17.06 (43.47$52.00)$. Some $44.4 \%$ of patients stated that they were cohabiting, $59.7 \%$ exerted a job, and $21.53 \%$ were retired, while $47,69 \%$ had been to higher level education. Almost all were covered under the French national health insurance, with $78.7 \%$ covered under the chronic conditions scheme.

NF1 diagnosis was made by a family physician in $25.9 \%$ of cases, a dermatologist in $38.9 \%$, and another specialist in $35.2 \%$. The family physician was involved in managing the disease in $35.4 \%$ of cases, and the dermatologist in $75.4 \%$. Altogether, $71.7 \%$ of patients stated they were satisfied with their current treatment, and $20 \%$ used self-medication.

Table 2 Description of the study population

\begin{tabular}{lll}
\hline & Men & Women \\
& $n=23(35.38 \%)$ & $n=42(64.62 \%)$ \\
\hline Age & 48.87 & 47.12 \\
Live alone & $39.13 \%$ & $28.57 \%$ \\
Higher level education & $56.52 \%$ & $42.86 \%$ \\
Diagnosis delay, if occurred (years) & 10.83 & 13.28 \\
living in a rural area & $30.43 \%$ & $14.29 \%$ \\
living in a mid size city & $47.83 \%$ & $40.48 \%$ \\
living in a large size city & $17.39 \%$ & $42.86 \%$ \\
\hline
\end{tabular}


There was no diagnostic delay for $36.9 \%$ of the patients. For those who did experience diagnostic delay, the waiting period was long, since 139.9 months (11.65 years) on average separated the first disease signs from definite diagnosis. About one-third of patients $(30.8 \%)$ were offered psychological treatment, and $16.9 \%$ had actually received it. Overall, $67 \%$ of the respondents were in contact with a patients association.

\section{Internal validity}

Principal component factor exploratory analysis was performed on the 17-item questionnaire. The correlation matrix was previously generated, and the maximum value was 0.8 . For all items, neither the answer "never" nor the answer "always" exceeded $20 \%$. Standardized regression coefficients were all > 0.4 (Additional file 1: Table S1), and each group of questions was assigned a dimension, with five dimensions as follows (Table 3):
- Dimension 1, with five questions on concentration and learning problems;

- Dimension 2, with five questions on the way others look at them and the anxiety they feel about the future;

- Dimension 3, with three questions on life with the disease;

- Dimension 4, with two questions on sexuality;

- Dimension 5, with two questions on acceptance and pain.

Confirmatory analysis revealed two questions not to be relevant, which were thus removed, resulting in a 15-item questionnaire, with four dimensions:

- Dimension 1, with five questions on concentration and learning problems;

- Dimension 2, with five questions on the way others look at them and the anxiety they feel about the future;

- Dimension 3, with three questions on life with the disease;

- Dimension 4, with two questions on sexuality.

Table 3 Loading of the questions on the factors after rotation

\begin{tabular}{|c|c|c|c|c|c|}
\hline & Factor1 & Factor2 & Factor3 & Factor4 & Factor5 \\
\hline $\begin{array}{l}\text { Do you think that your concentration problems } \\
\text { have had a negative impact on your work? }\end{array}$ & 0.88400 & 0.00039 & 0.11713 & 0.09071 & -0.09955 \\
\hline $\begin{array}{l}\text { Do you think that your concentration problems } \\
\text { have restricted your daily activities? }\end{array}$ & 0.88148 & 0.30780 & 0.09345 & -0.05582 & 0.06042 \\
\hline $\begin{array}{l}\text { During your education, do you think that you } \\
\text { had learning difficulties because of your NF1? }\end{array}$ & 0.79896 & -0.00429 & 0.21201 & 0.10511 & 0.06509 \\
\hline $\begin{array}{l}\text { Do you think that your concentration problems } \\
\text { have hindered your inclusion in society? }\end{array}$ & 0.73315 & 0.44034 & 0.26651 & -0.03789 & 0.06598 \\
\hline Have you had any difficulties in asking for help? & 0.60144 & 0.03367 & 0.57266 & 0.10930 & 0.01459 \\
\hline Have you perceived your NF1 as a physical disability? & 0.12939 & 0.88082 & 0.17472 & 0.09128 & 0.01365 \\
\hline $\begin{array}{l}\text { Because of your NF1, has the way other people } \\
\text { look at you caused you to suffer? }\end{array}$ & 0.05429 & 0.75423 & 0.01311 & 0.31858 & 0.09864 \\
\hline $\begin{array}{l}\text { Has your NF1 affected which clothes you choose } \\
\text { to wear? }\end{array}$ & -0.03823 & 0.63127 & 0.34293 & 0.41378 & -0.19180 \\
\hline $\begin{array}{l}\text { Have you felt that you have no control over what } \\
\text { is happening to you? }\end{array}$ & 0.38068 & 0.62787 & 0.33170 & -0.05902 & 0.26411 \\
\hline $\begin{array}{l}\text { Are you sometimes afraid of the future because } \\
\text { of your NF1? }\end{array}$ & 0.28498 & 0.55738 & 0.53923 & 0.32267 & 0.09847 \\
\hline $\begin{array}{l}\text { Has the paperwork in connection with your NF1 } \\
\text { been difficult? }\end{array}$ & 0.16269 & 0.14724 & 0.87805 & 0.06822 & 0.04185 \\
\hline $\begin{array}{l}\text { Have you felt that your socio-economic status may } \\
\text { be directly linked to your NF1? }\end{array}$ & 0.31203 & 0.47696 & 0.62411 & 0.02013 & 0.03600 \\
\hline Have you felt the need to justify yourself? & 0.35859 & 0.31300 & 0.51316 & 0.34404 & -0.00448 \\
\hline Do you think your NF1 has made you shyer? & -0.14253 & 0.13130 & 0.18588 & 0.81264 & 0.16481 \\
\hline Has your NF1 hindered your sexuality? & 0.30992 & 0.26387 & -0.00112 & 0.75537 & 0.04124 \\
\hline $\begin{array}{l}\text { Have you succeeded in managing (or dealing with) } \\
\text { your NF1 pain? }\end{array}$ & 0.01640 & 0.11954 & 0.10323 & -0.00897 & 0.82165 \\
\hline $\begin{array}{l}\text { Have you come to terms with the administrative } \\
\text { difficulties that you have encountered? }\end{array}$ & 0.01270 & -0.0229 & -0.0461 & 0.16370 & 0.81977 \\
\hline
\end{tabular}


The questionnaire's uni-dimensionality was confirmed by higher order factor analysis (Additional file 2: Table S2). The practical goodness-of-fit indices were acceptable, with a Bentler comparative fit index of 0.9521 and a Bentler-Bonett non-normed fit index of 0.9355 . The model appears well adjusted and well fitted, offering the possibility to group the four dimensions into one single score. All dimensions were found well correlating with the overall score (Table 4).

Cronbach's alpha coefficient was 0.91 for the entire questionnaire, reflecting its excellent internal coherence, while intradimensional coherences exhibiting good reliability.

\section{External validity}

The BoN questionnaire highly correlated with the Dermatology Life Quality Index (DLQI), Perceived Stress Scale (PSS), and SF12 mental scores (Table 5). The correlation coefficients between $\mathrm{BoN}$ and validated questionnaires were relatively high, confirming BoN's external validity; the correlation with the SF12 physical score proved the weakest.

Cognitive debriefing did not result in any major changes to the questions' wording.

\section{Test-retest analysis}

The test-retest reliability was obtained on 23 evaluable subjects (Day 1 and Day 10), demonstrating good reproducibility. The intraclass correlation of each dimension was $>0.85$ for each domain.

\section{Translation and cultural adaptation}

The original BoN French version was translated, then linguistically and culturally validated in US English.

While the original BoN questionnaire was developed in French, previously validated methodology was applied in order to generate an US English-language version, involving linguistic and cross-cultural validation 21 . This rigorous process comprises a meticulous 9 -step procedure and was meant to refine the translation while taking into account nuances of the source document. Briefly, source text evaluation from a linguistic and cultural perspective, including a clear definition of various concepts, was first carried out. In a second step, a separate translation of the text into US English by two independent translators was made. A comparison of the two translations with subsequent text optimization aiming to produce a preliminary draft questionnaire was then performed. Further, a back-translation and back-translation review were

Table 4 Cronbach's alpha for the four dimensions

\begin{tabular}{ccccc}
\hline & Factor 1 & Factor 2 & Factor 3 & Factor 4 \\
\hline Standardized a & 0.90 & 0.86 & 0.78 & 0.62 \\
\hline
\end{tabular}

Table 5 Correlations between the scores

\begin{tabular}{ll}
\hline & $\begin{array}{l}\text { Pearson correlation coefficients, } N=65 \\
\end{array}$ \\
& Prob $>|r|$ under H0: Rho $=0$ \\
\hline DLQI & 0.69930 \\
& $<.0001$ \\
& 0.72643 \\
PSS & $<.0001$ \\
& -0.57650 \\
SF12 -MCS & $<.0001$ \\
& -0.26242 \\
SF12 -Physical & 0.0347 \\
&
\end{tabular}

DLQI Dermatology Life Quality Index, PSS Perceived Stress Scale, PCS Physical Composite Score /SF12, MCS Mental Composite Score /SF12

performed in which retranslation of the draft questionnaire into the original language and comparison of the original questionnaire against the version obtained from back-translation was done to check whether the overall meaning of the reconciled translation matched that of the source document. Afterwards, to allow pilot testing of the questionnaire, an analysis of the back-translation and implementation of the back-translation review report was performed. Finally, before correction and finalization, a review of cognitive debriefing was performed.

However, from this US English version, an adequate validation in the US patients is still required.

Both versions are presently available (Table 6).

\section{BoN scoring}

The $\mathrm{BoN}$ can be expressed as a total score between 0 and 75 , where 0 represents no impact and 75 the highest possible impact. The total score is obtained by summing up the scores for each of the 15 questions. In our patient cohort, the mean BoN score obtained was 28.42 $( \pm 16.87)$, the mean score for men being $22.48( \pm 16.47)$ versus $31.67( \pm 16.38)$ for women $(p<0.001)$. The Shapiro test of normality for the $\mathrm{BoN}$ score provided a $p$-value of 0.15 , meaning that the hypothesis that the data are normally distributed can-not be rejected.

The respondents evaluated disease severity on a visual analog scale between 1 and 5, with 1 being low severity and 5 very high severity. The subjects were divided into three groups, namely low severity (scores of 1 and 2), moderate severity (3), and high severity (4 and 5 ). The BoN score of the low severity group was $17.6( \pm 11.9)$, while that of the moderate severity group was 29.3 $( \pm 14.4)$, and that of the high severity group $45.5( \pm 18.2)$, the BoN score differences statistically significant. Table 7 compares BoN score evolution according to severity, to the evolution of the other validated scores.

The mean BoN score was calculated for subjects who stated that they experienced diagnostic delay versus those who did not. BoN score for patients reporting a diagnostic delay was $30.3( \pm 15.4)$ versus $23( \pm 13.9)$ for 
Table 6 Burden of adult neurofibromatosis 1 questionnaire in English US and French

Do you think that your concentration problems have had a negative impact on your work?

Do you think that your concentration problems have restricted your daily activities?

During your education, do you think that you had learning difficulties because of your NF1?

Do you think that your concentration problems have hindered your inclusion in society?

Have you had any difficulties in asking for help?

Have you perceived your NF1 as a physical disability?

Because of your NF1, has the way other people look at you caused you to suffer?

Has your NF1 affected which clothes you choose to wear?

Have you felt that you have no control over what is happening to you?

Are you sometimes afraid of the future because of your NF1?

Has the paperwork in connection with your NF1 been difficult?

Have you felt that your socio-economic status may be directly linked to your NF1?

Have you felt the need to justify yourself?

Do you think your NF1 has made you shyer?

Has your NF1 hindered your sexuality?

Possible answers to each question and associated score

"never" or "not applicable" (0)
"rarely" (1)
"sometimes" (2)
"often" (3)
"very often" (4)
"constantly" (5)

those without, the between-group difference being statistically significant $(p=0.04)$.

\section{Discussion}

NF1 has been associated with impaired QoL [33], representing an attack on the patients' self-esteem and lifestyle [34]. In a cross-sectional study involving 176 adult NF1 cases, participants experienced a significant impact in all aspects of skin-disease-specific QoL [35].

Table 7 Scores of validated scales according to severity

\begin{tabular}{lllllll}
\hline Severity & N & PSS & DLQ & PCS & MCS & BoN \\
\hline Low & 20 & 24.34 & 6.58 & 52.67 & 45.63 & 44.55 \\
Moderate & 34 & 25.23 & 5.44 & 46.78 & 44.04 & 45.70 \\
High & 11 & 31.82 & 10.73 & 47.19 & 40.08 & 65.73 \\
\hline DLOI
\end{tabular}

DLQ/ Dermatology Life Quality Index, PSS Perceived Stress Scale, PCS Physical Composite Score /SF12, MCS Mental Composite Score /SF12
Pensez-vous que vos difficultés de concentration ont limité vos activités quotidiennes?

Considérez-vous, que vos difficultés de concentration ont eu un impact négatif dans votre travail?

En raison de votre Neurofibromatose de type 1, lors de votre scolarité, avez-vous rencontré des difficultés d'apprentissage?

Pensez-vous que vos difficultés de concentration ont été un frein à votre intégration dans la société?

Avez -vous éprouvé des difficultés à demander de l'aide?

Avez-vous ressenti votre Neurofibromatose de type 1 comme un handicap physique?

En raison de votre Neurofibromatose de type 1, le regard des autres a-t-il été pénible?

Avez-vous eu le sentiment d'avoir d'un destin imposé?

Votre Neurofibromatose de type 1, a-t-elle eu une influence sur le choix des vêtements que vous portez?

Vous arrive-t-il, de craindre l'avenir en raison de votre Neurofibromatose de type 1 ?

Les démarches administratives en lien avec votre Neurofibromatose de type 1 ont-elles été difficiles?

Avez-vous eu le sentiment que votre statut social ait été directement lié à votre Neurofibromatose de type 1?

Avez-vous eu le sentiment d'avoir besoin de vous justifier?

Avez-vous pensé que votre Neurofibromatose de type 1 vous rende plus timide?

Votre Neurofibromatose de type 1 a-t-elle été un obstacle (un frein) à votre sexualité?

"jamais" ou non applicable (0)

"rarement" (1)

"quelques fois "(2)

"souvent" (3)

"très souvent" (4)

"en permanence" (5)
Participants with more visible NF1 signs reported significantly greater overall effects on their skin-disease-specific QoL compared to those with more subtle manifestations. In a Spanish study on NF1 children, an extremely high frequency of cognitive disorders was reported [36]. In an Italian survey involving 129 NF1 adult patients, cosmetic features exerted the greatest impact on QoL [37].

The individual burden is increasingly investigated in the healthcare domain, taking into account QoL, community integration, organization of everyday life, and medical resource consumption [18]. With such specific questionnaires, it is possible to directly evaluate the overarching burden of a particular disease [19, 20, 22, 24]. Due to the advances in QoL research, the pharmaceutical industry, medical device industry, and regulatory agencies are now faced with complex issues related to health-related quality of life claims [38]. Leidy et al. generated recommendations 
to the healthcare industry for assuring that all health-related QoL claims be based on rigorously-designed studies [38]. Several developments in clinical research have led to a widespread use of questionnaires. The reason for this is the increasing relevance of patient-reported outcome data to achieve market access. Quality of life, patient wellbeing, and patient-centered outcomes are increasingly requested by reimbursement agencies [39].

This report provides support for BoN's feasibility, reliability, and validity as a specific instrument designed to assess the individual disease burden in adult NF1. The specificity of the BoN questionnaire is that it measures the burden and the impact that NF1 generates in a patient's daily life. The items are directly derived from discussions conducted by a psychologist with 45 patients with NF1 over a period of 1 year. This is why these items reflect disabilities specific to NF1 such as neurological problems including difficulties in vision, impaired sustained attention, or learning difficulties. Let us add that the burden caused by the disease on many practical aspects of daily activities go beyond the notion of quality of life and are described in the very specific wording expressed by the patients themselves.

With its 15 items and six possible answers for each, this questionnaire is relatively short, understandable and easy-to-use by the patients. BoN has been proven a robust tool, its internal consistency exceeding the minimum reliability criterion of 0.90 . This supports using the total BoN score as a distinct measure of the individual disease burden in adult NF1 patients.

In our research, $\mathrm{BoN}$ version was able to discriminate between low, moderate, and high disease severity, supporting the tool's discriminant validity. Consistent with our hypothesis, high BoN scores were associated with adult patients reporting high disease severity on a visual analog scale, whereas low BoN scores were linked to those reporting low disease activity. The mean BoN score proved able to differentiate patients with delayed NF1 diagnosis from those with no delay. Moreover, BoN was shown to exhibit external validity, correlating well with the other validated QoL scales.

Our study exhibits several limitations, the largest one being its relatively small sample size of 65 accessible patients. In this regard, we used a Kaiser-Meyer-Olkin measure to explore the sampling adequacy, and all values were greater than 0.6 , except for the 2 items that were removed.

Another limitation is the sole use of BoN in adult patients, as the tool has not yet been validated in children.

We hope that this BoN questionnaire will serve as a valuable tool for healthcare providers to better follow up their patients' improvement, and adjust NF1 patient management accordingly. This burden evaluation will likely facilitate communication between patients and healthcare providers, improve information transfer, and create a real opportunity for the practitioner to better understand certain issues brought up by the patient.

\section{Conclusions}

The BoN demonstrates feasibility, reliability, and discriminant validity. This instrument can thus be employed to better understand the multidimensional nature of NF1 on the individual burden of adult patients. This tool may similarly have a role to play in the decision-making process.

\section{Additional files}

Additional file 1: Eigenvalues of the factors. (DOCX $15 \mathrm{~kb}$ )

Additional file 2: Model assessment parameters. (DOCX $17 \mathrm{~kb}$ )

\section{Abbreviations}

BoN: Burden of neurofibromatosis 1; DLQI: Dermatology Life Quality Index; MCS-SF12: Mental Composite Score- Short Form 12; NF1: Neurofibromatosis type 1; PCS-SF12: Physical Composite Score- Short Form 12; PSS: Perceived Stress Scale; QoL: Quality of life; RMSEA: Root mean square error of approximation

\section{Acknowledgements}

The authors thank the patient association for helping and supporting this project.

\section{Funding \\ The project has received public funding from Fimarad (French network of rare skin disorders, Necker Hospital, Paris, France).}

\section{Availability of data and materials}

The datasets used and/or analyzed during the current study are available from the corresponding author on reasonable request.

\section{Authors' contributions}

$C T, M L A$ and $A B$ conceived the study, participated in its design and coordination and helped drafting the manuscript. $C B, P W$, and $M B$ participated in the design of the study and conceptual phase. MB performed the statistical analysis. All authors read, commented on, and approved the final manuscript.

\section{Ethics approval and consent to participate}

The questionnaire construction was carried out as part of the RADICO-FARD project, which obtained a favorable opinion from the Committee for the Protection of Individuals (CPP Ouest V, Rennes) on July 31, 2017. The questionnaire was proposed by the patient association, and at no time did the authors of the project or the persons in charge of the analgesia statistics know the identity of the responders.

There was no way to make a connection between the answers obtained and the person who answered the questionnaire.

The respondents were provided with an information sheet before giving their consent. This information sheet as well as the consent form clearly explained the purpose of the project and guaranteed the anonymity of the responses.

\section{Consent for publication}

Not applicable.

\section{Competing interests}

The authors declare that they have no competing interests.

\section{Publisher's Note}

Springer Nature remains neutral with regard to jurisdictional claims in published maps and institutional affiliations. 


\section{Author details}

'Department of Dermatology, Hôpital Henri Mondor, Créteil, France. ${ }^{2}$ FIMARAD, French rare diseases Healthcare Network: rare dermatologic disease, CHU Paris - Hôpital Necker-Enfants Malades, 149 rue de Sèvres, 75743 Paris, France. ${ }^{3}$ Association Neurofibromatoses et Recklinghausen, patients association, Neuville-en-Ferrain, France. ${ }^{4}$ Qualees, Paris, France. ${ }^{5}$ MAGEC center of excellence for rare skin diseases, Necker-Enfants Malades University Hospital, Paris, France.

Received: 13 September 2018 Accepted: 17 April 2019

Published online: 03 May 2019

\section{References}

1. Cawthon RM, Weiss R, Xu GF, Viskochil D, Culver M, Stevens J, et al. A major segment of the neurofibromatosis type 1 gene: CDNA sequence, genomic structure, and point mutations. Cell. 1990;62:193-201.

2. Xu GF, O'Connell P, Viskochil D, Cawthon R, Robertson M, Culver M, et al. The neurofibromatosis type 1 gene encodes a protein related to GAP. Cell. 1990;62:599-608.

3. Martin GA, Viskochil D, Bollag G, McCabe PC, Crosier WJ, Haubruck H, et al. The GAP-related domain of the neurofibromatosis type 1 gene product interacts with ras p2. Cell. 1990;63:843-9.

4. Rasmussen SA, Friedman JM. NF1 gene and neurofibromatosis 1. Am J Epidemiol. 2000;151:33-40.

5. Evans DG, Howard E, Giblin C, Clancy T, Spencer H, Huson SM, et al. Birth incidence and prevalence of tumor-prone syndromes: estimates from a UK family genetic register service. Am J Med Genet. 2010;152:327-32.

6. Gutmann DH, Aylsworth A, Carey JC, Korf B, Marks J, Pyeritz RE, et al. The diagnostic evaluation and multidisciplinary management of neurofibromatosis 1 and neurofibromatosis 2. JAMA. 1997;278:51-7.

7. Griffiths S, Thompson P, Frayling I, Upadhyaya M. Molecular diagnosis of neurofibromatosis type 1:2 years experience. Familial Cancer. 2006;6:21-34.

8. Hirbe AC, Gutmann DH. Neurofibromatosis type 1: a multidisciplinary approach to care. Lancet Neurol. 2014;13:834-43.

9. Sorensen SA, Mulvihill JJ, Nielsen A. Long-term follow-up of von Recklinghausen neurofibromatosis. Survival and malignant neoplasms. N Engl J Med. 1986;314:1010-5.

10. Hernández-Martín A, Duat-Rodríguez A. An update on neurofibromatosis type 1: not just café-au-lait spots and freckling. Part II. Other skin manifestations characteristics of NF1. NF1 and cancer. Actas Dermosifiliogr. 2016;107:465-73.

11. Belzeaux R, Lançon C. Neurofibromatosis type 1: psychiatric disorders and quality of life impairment. Presse Med. 2006;35:277-80.

12. Burris $\mathrm{CKH}$, Stier MA, Salamat S, Thomas S, Lauderdale S, Raven ML, et al. Neurofibromatosis type 1: a neuro-psycho-cutaneous syndrome? Orbit. 2017:20:1-4.

13. Pasini A, Lo-Castro A, Di Carlo L, Pitzianti M, Siracusano M, Rosa C, Galasso C. Detecting anxiety symptoms in children and youths with neurofibromatosis type I. Am J Med Genet B Neuropsychiatr Genet. 2012; 159:869-73.

14. Vranceanu AM, Merker VL, Park E, Plotkin SR. Quality of life among adults with neurofibromatosis 1, neurofibromatosis 2 and schwannomatosis: a systematic review of the literature. J Neuro-Oncol. 2013;114:257-62.

15. Michaud CM, McKenna MT, Begg S, Tomijima N, Majmudar M, Bulzacchelli MT, et al. The burden of disease and injury in the United States 1996. Popul Health Metrics. 2006:4:11.

16. Chren MM, Weinstock MA. Conceptual issues in measuring the burden of skin diseases. J Investig Dermatol Symp Proc. 2004;9:97-100.

17. World Health Organization, WHO. About the Global Burden of disease (GBD) project; 2010, http://www.who.int/healthinfo/global_burden_disease/about/ en/. (Accessed 26 Apr 2019).

18. Meyer N, Paul C, Feneron D, Bardoulat I, Thiriet C, Camara C, et al. Psoriasis: an epidemiological evaluation of disease burden in 590 patients. J Eur Acad Dermatol Venereol. 2010;24:1075-82.

19. Boccara O, Méni C, Léauté-Labreze C, Bodemer C, Voisard J, Dufresne H, et al. Haemangioma family burden: creation of a specific questionnaire. Acta Derm Venereol. 2015;95:78-82.

20. Dufresne H, Hadj-Rabia S, Méni C, Sibaud V, Bodemer C, Taïeb C. Family burden in inherited ichthyosis :creation of a specific questionnaire. Orphanet J Rare Dis. 2013;8:28.
21. Taïeb A, Boralevi F, Seneschal J, Merhand S, Georgescu V, Taieb C, Ezzedine K. Atopic dermatitis: development and validation of a new assessment tool. Acta Derm Venereol. 2015;95:700-5.

22. Salzes $C$, Abadie $S$, Seneschal J, Whitton M, Meurant JM, Jouary T, et al. The vitiligo impact patient scale (VIPs): development and validation of a vitiligo burden assessment tool. J Invest Dermatol. 2016;136:52-8.

23. Ferner RE, Thomas M, Mercer $G$, et al. Evaluation of quality of life in adults with neurofibromatosis 1 (NF1) using the impact of NF1 on quality of life (INF1-QOL) questionnaire. Health Qual Life Outcomes. 2017;15(1):34.

24. Seidenberg M, Haltiner A, Taylor MA, Hermann BB, Wyler A. Development and validation of a multiple ability self-report questionnaire. J Clin Exp Neuropsychol. 1994;16:93-104.

25. Cronbach $\amalg$, Warrington WG. Time-limit tests: estimating their reliability and degree of speeding. Psychometrika. 1951;6:167-88.

26. Bentler PM. Comparative fit indexes in structural models. Psychol Bull. 1990; 107:238-46.

27. Finlay AY, Khan GK. Dermatology life quality index (DLQI)--a simple practical measure for routine clinical use. Clin Exp Dermatol. 1994;19:210-6.

28. Lewis $V$, Finlay AY. 10 years experience of the dermatology life questionnaire. J Investig Dermatol Symp Proc. 2004;9:169-80.

29. Cohen S, Kamarck T, Mermelstein R. A global measure of perceived stress. J Health Soc Behav. 1983;24:385-96.

30. Cohen $S$, Williamson G. Perceived stress in a probability sample of the United States. In: Spacapan S, Oskamp S, editors. The social psychology of health: Claremont symposium on applied social psychology. Newbury Park: Sage; 1988.

31. Lim LL, Fisher JD. Use of the 12-item short-form (SF-12) health survey in an Australian heart and stroke population. Qual Life Res. 1999;8:1-8.

32. Wild D, Grove A, Martin M, Eremenco S, McElroy S, Verjee-Lorenz A, et al, Principles of good practice for the translation and cultural adaptation process for patient-reported outcomes (PRO) measures: report of the ISPOR task force for translation and cultural adaptation. Value Health. 2005;8:94-104.

33. Samuelsson B, Riccardi VM. Neurofibromatosis in Gothenburg, Sweden, III: psychiatric and social aspects. Neurofibromatosis. 1989;2:84-106.

34. Mauger D, Zeller J, Revuz J, Wolkenstein P. Psychological impact of neurofibromatosis type 1. Ann Dermatol Venereol. 1999;126:619-20.

35. Page PZ, Page GP, Ecosse E, Korf BR, Leplege A, Wolkenstein P. Impact of neurofibromatosis 1 on quality of life: a cross-sectional study of 176 American cases. Am J Med Genet A. 2006;140:1893-8.

36. Garcia-Penas JJ. Learning disorders in neurofibromatosis type 1. Rev Neurol. 2017:64:59-63.

37. Kodra Y, Giustini S, Divona L, Porciello R, Calvieri S, Wolkenstein P, et al. Health-related quality of life in patients with neurofibromatosis type 1. A survey of 129 Italian patients. Dermatology. 2009;218:215-20.

38. Leidy NK, Revicki DA, Genesté B. Recommendations for evaluating the validity of quality of life claims for labeling and promotion. Value Health. 1999;2:113-27.

39. Wagner T. Using questionnaires in clinical research - a guide through the data jungle. J Clin Study. 2014;6:52-4.

Ready to submit your research? Choose BMC and benefit from:

- fast, convenient online submission

- thorough peer review by experienced researchers in your field

- rapid publication on acceptance

- support for research data, including large and complex data types

- gold Open Access which fosters wider collaboration and increased citations

- maximum visibility for your research: over $100 \mathrm{M}$ website views per year

At BMC, research is always in progress.

Learn more biomedcentral.com/submissions 